\title{
The Strength Analysis of a Bus Superstructure Based on the Accuracy Improvement of T-Junction Flexible Joint Stiffness
}

\author{
Supakit Rooppakhun ${ }^{1 *}$, Jakkree Wichairahad ${ }^{2}$ \\ ${ }^{1}$ School of Mechanical Engineering, Institute of Engineering, Suranaree University of Technology, Nakhonratchasima, Thailand \\ ${ }^{2}$ School of Manufacturing Engineering, Institute of Engineering, Suranaree University of Technology, Nakhonratchasima, Thailand \\ *Corresponding authorE-mail: supakit@sut.ac.th
}

\begin{abstract}
The strength analysis of bus superstructure was extremely important that the manufacturer must take into account, especially in the maximum stress analysis as well as the construction stiffness. In this study, the finite element (FE) model of an intercity bus superstructure consisted of chassis frame and body structure has been analyzed based on the improved beam joint considerations. The accuracy improvement of beam type element model was performed using the equivalent joint stiffness of T-junction beam modeling, and then compared with shell and volume elements. According to the improved T-junction FE model, the flexible joint stiffness consideration has been obtained, in which the behavioral error was reduced to less than $6 \%$. The FE model of bus superstructure with improved beam joint was then compared to the rigid joint condition in bending, torsion, longitudinal and lateral load cases. The numerical results revealed that magnitude of maximum stress in the improved beam joint model displayed increasing of $11.53 \%, 14.11 \%$, and $18.45 \%$ in torsion, longitudinal and lateral load cases, respectively. However, the maximum stresses reduced in a case of bending with value of $5.72 \%$. In addition, the value of construction stiffness of improved beam joint model exhibited lower than the rigid beam joint as $44.85 \%$, and $10.68 \%$ in the bending and torsion load case, respectively. To improve the accuracy of computer simulation, it will be beneficial to the passenger and the bus structure design and improvement procedure.
\end{abstract}

Keywords: Strength Analysis, Bus Superstructure, Joint Stiffness, Finite Element Analysis.

\section{Introduction}

Nowadays, the transportation by intercity bus extremely plays important role in Thailand. It was found that the average number of people using the bus service is increasing steadily each year [1]. In the design and manufacture process of the intercity bus, the structural strength, fabrication difficulty as well as structure configuration are essential factors that manufacturer must take into account. The intercity bus superstructure is generally divided into two parts. One is a chassis frame which is a main component designing to resist a external load. Another part placed on the upper of chassis frame is called a body structure creating to accommodate passengers included utilities. The constructed body structure is similar to a skeleton frame consisted of many members with various cross-sectional shapes which serve to enhance the constructed stiffness of the bus superstructure as shown in figure 1.

Currently, the finite elements (FE) analysis is a computational technique which is widely used, especially in automotive industry for the process of design including the development of new product [2]. The FE modeling was generated to convert a physical geometry of the actual bus structure into an analytical model. However, the verification of $\mathrm{FE}$ analysis still continues to be extremely important for the reliability.

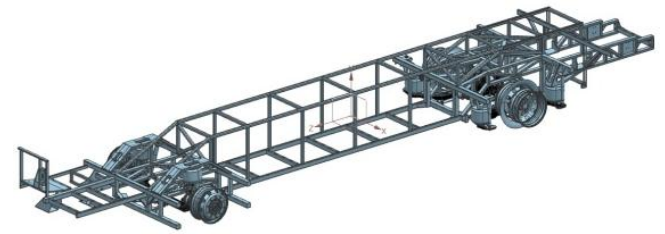

(a)

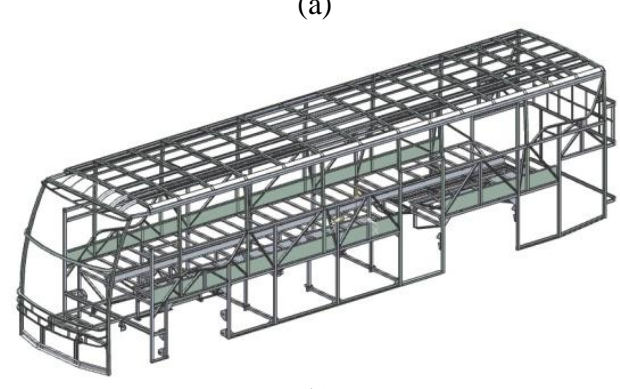

(b)

Fig. 1: Bus superstructure; (a) Chassis frame, (b) Body structure.

According to the structure requirements, the category of any structure can be generally described into 2 points. One is strength category characterized by the onset of permanent deformation including the allowable stress. Another is stiffness category which is the ratio of applied load per unit of deformation [3, 4]. The characteristic of construction stiffness can be divided into 2 sections following as bending stiffness $\left(K_{B}\right)$, and torsion stiffness $\left(K_{T}\right)$. It 
can be obtained from the ratio between applied load and deformation on bending and torsion case as shown in relation (1).

$$
K_{B}=\frac{W}{\delta}, \quad K_{T}=\frac{T}{\theta}
$$

Where:

W: total load $(\mathrm{N})$

T: torsion moment (N-mm)

$\delta:$ deformation (mm)

$\theta:$ twist angle (degree)

For large tubular structures such as the bus superstructure, beam type elements were utilized due to the fact that these elements provided satisfactory results at relatively reduced computational performances. The analyze system with non-complex beam equation provided reliability in the large structure simulation [5-8]. In addition, it is suggested that if the length of the member is 10 times larger than largest dimension of its cross section, the beam element is more suitable for an FE model generation. However, the infinite rigid behavior of beam joint modeling continues to be a limitation in the analysis. This imperfection decides an inflexible behavior of structures interpreting into an error cause for the structural analysis (up to 45\%) [9]. In previous studies, the reliability of bus structure was proposed using shell and volume element type analysis [2, 10]. The study of Alcala in 2013 [9] examined the square thin-walled cross section of T-junctions using beam element included the joint stiffness consideration. The behavioral characteristics of beam modeled determining their limitations and comparing to shell and volume elements. The result found that the behavioral error was reduced to less than $5 \%$.

In the study, the finite element of one model of intercity bus superstructure made from Cherdchai Industrial Factory Co.,Ltd. consisted of chassis frame and body structure was analyzed under global vehicle load case (e.g., bending, torsion, longitudinal, and lateral). For the accuracy improvement of beam joint, the equivalent flexible joint was evaluated by using T-junctions beam modeled. By this way, the joint stiffness matrix can be validated and compared to the shell and volume element. In addition, the FE model of bus superstructure with improved beam joint was then compared to the rigid joint condition. The strength analysis consisted of maximum stress, deformation, and construction stiffness was obtained.

\section{Material and Method}

\subsection{T- Junction Flexible Joint Stiffness Evaluation}

The 5 cross section of simple thin-walled T-junction joint structure consisted of 3 parts (the length of $500-\mathrm{mm}$ for part number 1 , and number 2 and the length of 1,000-mm for part 3) with equal square cross section and the dimension of 80-mm x 80-mm x 4$\mathrm{mm}, 40-\mathrm{mm} \times 80-\mathrm{mm} \times 4-\mathrm{mm}, 47-\mathrm{mm} \times 47-\mathrm{mm} \times 1.8-\mathrm{mm}, 23-$ $\mathrm{mm} \times 48.5-\mathrm{mm} \times 2-\mathrm{mm}$ and $25.6-\mathrm{mm} \times 25.6-\mathrm{mm} \times 2-\mathrm{mm}$ wear considered as shown in figure 2 . According to the beam joint modelling, a total of 6 parameters of stiffness matrix consisted of three linear, and three angular translations as following in equation (2) and (3), respectively.

$$
K_{B i}=\frac{F_{i}}{d_{i}}, \quad i=x, y, z
$$

Where:

$F_{i}$ : elastic element axial force corresponding to the $\mathrm{x}, \mathrm{y}$ and $\mathrm{z}$ directions $d_{i}$ : nodal displacement on the $\mathrm{x}, \mathrm{y}$ and $\mathrm{z}$ directions

$K_{T i}=\frac{M_{i}}{\theta_{i}}, \quad i=x, y, z$

Where:

$M_{i}$ : torsional moment corresponding to the $\mathrm{x}, \mathrm{y}$ and $\mathrm{z}$ directions $\theta_{i}:$ Twist angle

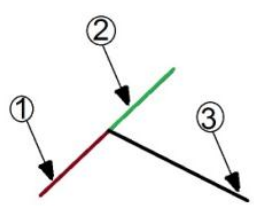

(a)

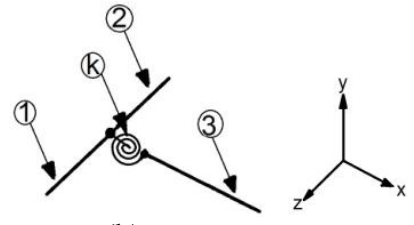

(b)
Fig. 2: A simple T-junction joint structures; (a) the three parts of real beam model, (b) the concept modelling of beam with flexible join stiffness.
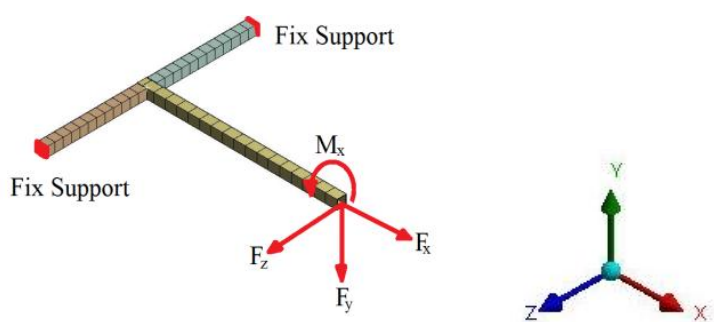

Fig. 3: FE model of T-junction beam including the boundary condition.

For the evaluation of T-junction flexible joint stiffness, the linear and angular translations under the four-type applied loads were evaluated from numerical and experimental method as shown in figure 3 to figure 5. Regard to the FE simulation, the material properties of T-junction beam were considered as linear isotropic material with the elastic modulus of $204 \mathrm{GPa}$, Poisson's ratio of 0.26 , and yield strength of $235 \mathrm{MPa}$ (obtained from the laboratory test). For the boundary condition, the end of part number 1 and number 2 were fixed support included the applied load at the end of part number 3 as shown in Figure 3

According to the experiment, the apparatus of T-junction beam testing with clamping and adjustable sliding guide was created for the linear and angular translation measurement by the digital dial gauge as shown in figure 4 and figure 5 , respectively. To measure the linear deformation, a mass was applied along the direction of $\mathrm{x}-, \mathrm{y}-$, and $\mathrm{z}$-axis as shown in figure 4. For angular deformation, the calculated torsion moment about $\mathrm{x}$-axis obtained from mass and the distance of lever arm $500 \mathrm{~mm}$. was performed as shown in Figure 5 .

\subsection{Strength Analysis of Bus Superstructure by Im- proved Flexible Joint Stiffness}

In order to the strength analysis, the FE model of bus superstructure was performed using finite element commercial software. The joint stiffness modeling of bus superstructure was considered. From previous section, the 5 sets of 6 parameters of stiffness matrix were defined in each T-junction of the skeleton structure. For the material properties assignment, the chassis frame was achieved with yield strength of $235 \mathrm{MPa}$, elastic modulus of $204 \mathrm{GPa}$, and the body structure was placed with yield strength of $370 \mathrm{MPa}$, Young modulus of $193 \mathrm{GPa}$ (obtained from the laboratory test).

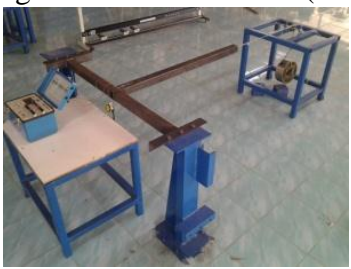

(a)

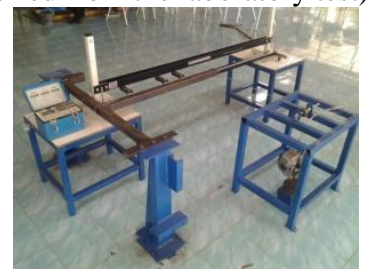

(b) 


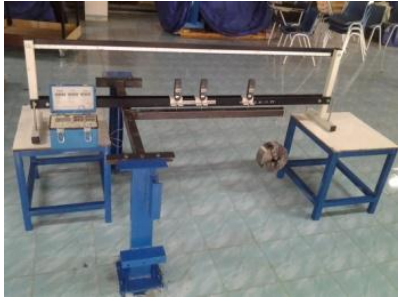

(c)

Fig. 4: The each direction of applied load on $\mathrm{T}$-junction beam including the digital dial gauge; (a) $\mathrm{X}$-axis, (b) Z-axis, (c) Y-axis.

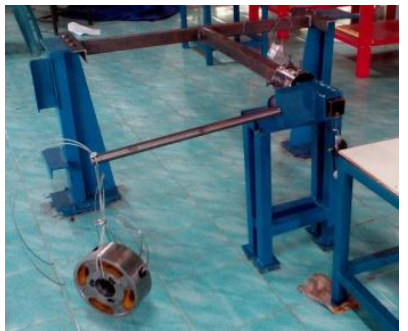

Fig. 5: The applied moment on $\mathrm{x}$-axis on the T-junction beam.

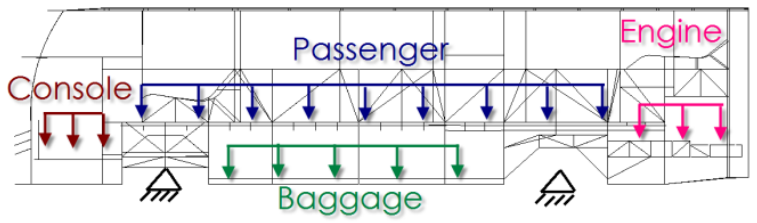

Fig. 6: The typically bending load case by subsystem weight consisted of console unit, passenger, baggage, and engine components.

According to the boundary condition and the total of 4 global load cases (e.g., bending, torsion, longitudinal, and lateral) they were performed as following; [3, 4]

Bending load case; a total of 4 components consisted of the engine component of $6,730 \mathrm{~N}$., the front console weight of $3,000 \mathrm{~N}$. (from parts data sheet) the passenger weight of $31,280 \mathrm{~N}$., the passenger baggage of 7,000 N. (measured from real load at same bus model series), and the construction weight of 21,766 N. (from CAD simulation), was considered as a vehicle at rest including the simply support at 4 wheel hub condition as shown in Figure 6.

Torsion load case; a wheel climbed a curb accidentally was considered. The vertical displacement was applied to one wheel hub with a lamp up of $200 \mathrm{~mm}$, while other three wheels were attached at the ground.

Longitudinal load case; the acceleration or deceleration responds was performed in longitudinal direction. From the previous study, the severe acceleration load of $0.75 \mathrm{~g}$ was recommended for this case.

Lateral load case; a lateral acceleration was used to simulate the cornering maneuver. For a severe drive, a lateral acceleration of $0.75 \mathrm{~g}$ was employed to obtain both sides of a turning response.

\section{Results and Discussions}

\subsection{T - Junction Flexible Joint Beam Element Evalua- tion}

Table 1 and 2 displayed the results of 6-DOF parameter of flexible joints stiffness matrix of thin-hollow square cross section 47-mm x 47-mm x 1.8-mm beam calculated from deformation results by experimental compared with FE rigid joint beam element results and previous equation (2) and (3). Then, there was input the 6DOF of flexible joints parameter in the FE simulation (Flexible joint beam element type). Figure 7 showed the deformation results of T-junction structure in different element type compared with experimental results. It can be noticed that all corresponding among 5 models illustrated a very similar trend. However, there was the flexible joint beam element despite a small discrepancy from the result of experimental method. The result showed that the accuracy of beam deformation could be improved using the method of flexible joint stiffness compensation. By this way, the flexible joint matrixes were corrected which the beam properties can be calculated to match the rotational stiffness.

Table 1: Results of 3 DOF linear flexible joint stiffness matrixes (47-mm x 47-mm x 1.8-mm)

\begin{tabular}{lcccc}
\hline & X direction & Y direction & $\begin{array}{c}\text { Z direc- } \\
\text { tion }\end{array}$ \\
\hline $\begin{array}{l}\text { Experimental defor- } \\
\text { mation at joint }(\mathrm{mm})\end{array}$ & 0.24 & 0.10 & 0.08 \\
\hline $\begin{array}{l}\text { FE. deformation at joint } \\
(\mathrm{mm})\end{array}$ & 0.13 & 0.01 & 0.06 \\
\hline $\mathrm{d}_{\mathrm{x}}(\mathrm{mm})$ & 0.11 & 0.09 & 0.02 \\
\hline Load, $\mathrm{F}_{\mathrm{x}}(\mathrm{N})$ & 127.53 & 127.53 & 127.53 \\
\hline $\begin{array}{l}\text { Linear flexible joint } \\
\text { Parameter value }\left(\mathrm{F}_{\mathrm{i}} / \mathrm{d}_{\mathrm{i}}\right)\end{array}$ & 1,159 & 1,482 & 8,502 \\
$(\mathrm{~N} / \mathrm{mm})$. & & & \\
\hline
\end{tabular}

Table 2: Results of 3 DOF torsion flexible joint stiffness matrixes

\begin{tabular}{lcccc}
\multicolumn{1}{c}{ Axis } & $\mathbf{X}$ & $\mathbf{Y}$ & $\mathbf{Z}$ \\
\hline $\begin{array}{l}\text { Experimental twist angle } \\
\text { (Degree) }\end{array}$ & 0.42 & 0.18 & 0.25 \\
\hline FE. Twist angle (Degree) & 0.30 & 0.12 & 0.23 \\
\hline$\theta_{\mathrm{i}}($ Degree) & 0.12 & 0.06 & 0.02 \\
\hline $\begin{array}{l}\text { Moment, } \mathrm{M}_{\mathrm{i}} \\
\text { (N-mm) }\end{array}$ & 69,925 & 127,530 & 127,530 \\
\hline $\begin{array}{l}\text { Torsion flexible joint } \\
\text { parameter value }\left(\mathrm{M}_{\mathrm{i}} / \theta_{\mathrm{i}}\right) \\
\text { (N-mm./degree) }\end{array}$ & 588,447 & $2,023,486$ & $5,079,292$ \\
& & & \\
\hline
\end{tabular}

Table 3: The deviation of deformation respected to experiment (47-mm x 47-mm x 1.8-mm)

\begin{tabular}{c|c|c|c|c|c}
\hline \multirow{2}{*}{ Load } & \multicolumn{5}{|c}{ \% Error } \\
\cline { 2 - 6 } & \multicolumn{5}{|c}{ Element type } \\
\cline { 2 - 6 } & Solid & Surface & $\begin{array}{c}\text { Mix } \\
\text { beam- } \\
\text { surface }\end{array}$ & $\begin{array}{c}\text { Beam } \\
\text { rigid } \\
\text { joint }\end{array}$ & $\begin{array}{c}\text { Beam } \\
\text { flexible } \\
\text { joint }\end{array}$ \\
\hline Linear X & 35.42 & 33.33 & 29.16 & 45.83 & 0.97 \\
Linear Y & 16.40 & 16.05 & 16.85 & 17.34 & 4.06 \\
Linear Z & 46.66 & 45.64 & 42.82 & 40.00 & 5.97 \\
Torsion X & 27.99 & 14.80 & 42.07 & 21.98 & 0.05 \\
\hline
\end{tabular}

Table 3 showed the result of the deviation of beam deformation in each applied load direction compared to the experiment. It could be noticed that the FE beam element using flexible joint beam element has the lowest error for those other. This was clearly identified that FE beam flexible joint or compensated joint modeling approach could have an equivalent solution to other element that agreed with the study of E. Alcala et al. [9]

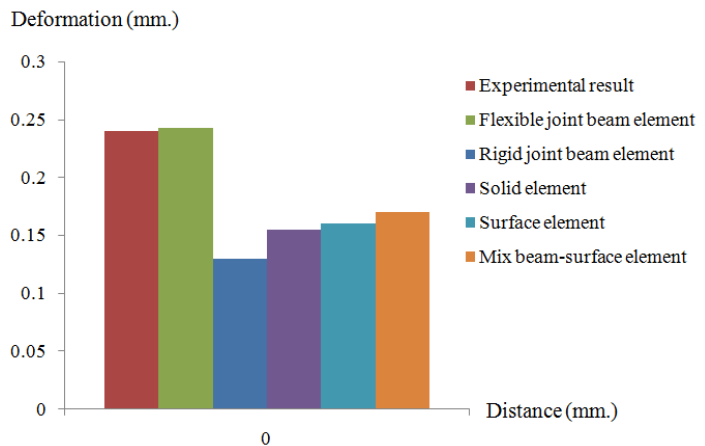

(a) 


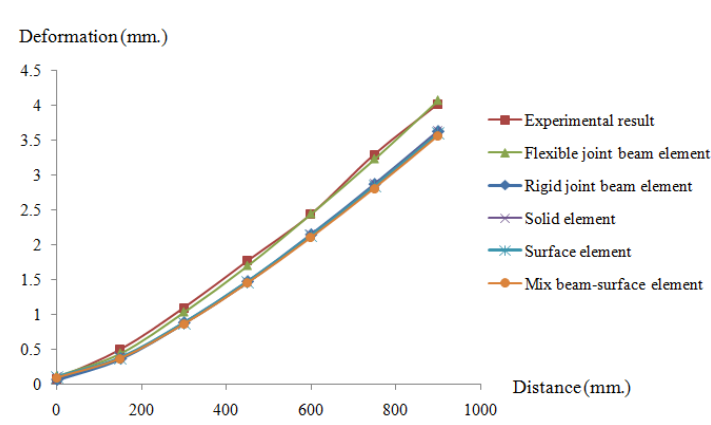

(b)

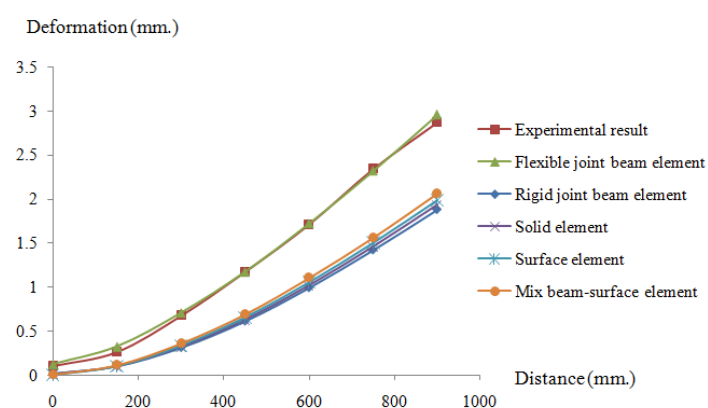

(c)

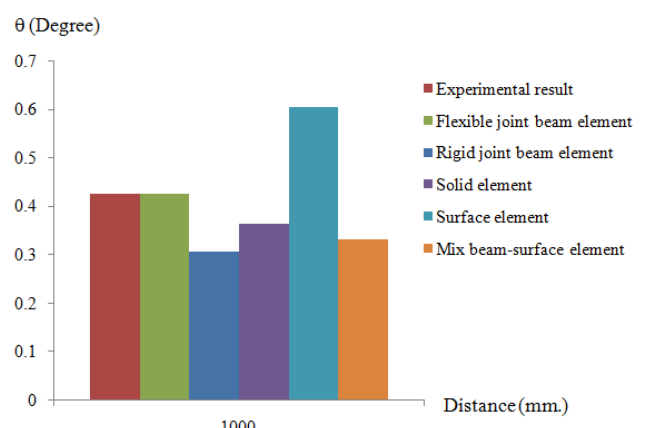

(d)

Fig. 7: The result of beam deformation in different element types respected to the experimental result; (a) Applied load on X-axis, (b) Applied load on Y-axis, (c) Applied load on Z-axis, (d) the angular deformation when applied bending moment on $\mathrm{X}$ - axis.

Table 4 to 11 displayed the results of 6-DOF parameter of flexible joints stiffness matrix of other cross section of thin-hollow square cross section beam.

Table 4: Results of 3 DOF linear flexible joint stiffness matrixes (80-mm x 80-mm x 4-mm)

\begin{tabular}{lcccc}
\hline & X direction & Y direction & $\begin{array}{c}\text { Z direc- } \\
\text { tion }\end{array}$ \\
\hline $\begin{array}{l}\text { Experimental deformation at } \\
\text { joint }(\mathrm{mm})\end{array}$ & 0.186 & 0.148 & 0.208 \\
\hline $\begin{array}{l}\text { FE. deformation at joint } \\
(\mathrm{mm})\end{array}$ & 0.007 & 0.027 & 0.009 \\
\hline $\mathrm{d}_{\mathrm{x}}(\mathrm{mm})$ & 0.179 & 0.121 & 0.199 \\
\hline Load, $\mathrm{F}_{\mathrm{x}}(\mathrm{N})$ & 255.06 & 255.06 & 255.06 \\
\hline $\begin{array}{l}\text { Linear flexible joint Parame- } \\
\text { ter value }\left(\mathrm{F}_{\mathrm{i}} / \mathrm{d}_{\mathrm{i}}\right)(\mathrm{N} / \mathrm{mm} \text {.) }\end{array}$ & 1,425 & 2,116 & 1,285 \\
\hline
\end{tabular}

Table 5: Results of 3 DOF torsion flexible joint stiffness matrixes

\begin{tabular}{lcccc}
\multicolumn{4}{c}{$(80-\mathrm{mm} \times 80-\mathrm{mm} \times 4-\mathrm{mm})$} \\
\hline \multicolumn{1}{c}{ Axis } & $\mathbf{X}$ & $\mathbf{Y}$ & $\mathbf{Z}$ \\
\hline $\begin{array}{l}\text { Experimental twist } \\
\text { angle (Degree) }\end{array}$ & 0.097 & 0.140 & 0.056 \\
\hline $\begin{array}{l}\text { FE. Twist angle (De- } \\
\text { gree) }\end{array}$ & 0.058 & 0.045 & 0.022 \\
\hline$\theta_{\mathrm{i}}($ Degree) & 0.039 & 0.095 & 0.034 \\
\hline $\begin{array}{l}\text { Moment, } \mathrm{M}_{\mathrm{i}} \\
\text { (N-mm) }\end{array}$ & 168,339 & 251,234 & 251,234 \\
\hline
\end{tabular}

\begin{tabular}{llll}
$\begin{array}{l}\text { Torsion flexible joint } \\
\text { parameter value }\left(\mathrm{M}_{\mathrm{i}} / \theta_{\mathrm{i}}\right)\end{array}$ & $4,349,165$ & $2,647,137$ & $7,228,812$ \\
$(\mathrm{~N}-\mathrm{mm} . /$ degree $)$ & & & \\
\hline
\end{tabular}

Table 6: Results of 3 DOF linear flexible joint stiffness matrixes (40-mm x 80-mm x 4-mm)

\begin{tabular}{lcccc}
\hline & X direction & Y direction & $\begin{array}{c}\text { Z direc- } \\
\text { tion }\end{array}$ \\
\hline $\begin{array}{l}\text { Experimental deformation at } \\
\text { joint }(\mathrm{mm})\end{array}$ & 0.226 & 0.088 & 0.086 \\
\hline $\begin{array}{l}\text { FE. deformation at joint } \\
(\mathrm{mm})\end{array}$ & 0.016 & 0.020 & 0.016 \\
\hline $\mathrm{d}_{\mathrm{x}}(\mathrm{mm})$ & 0.210 & 0.068 & 0.070 \\
\hline Load, $\mathrm{F}_{\mathrm{x}}(\mathrm{N})$ & 127.53 & 127.53 & 127.53 \\
\hline $\begin{array}{l}\text { Linear flexible joint Parame- } \\
\text { ter value }\left(\mathrm{F}_{\mathrm{i}} / \mathrm{d}_{\mathrm{i}}\right)(\mathrm{N} / \mathrm{mm} .)\end{array}$ & 607 & 1,875 & 1,837 \\
\hline
\end{tabular}

Table 7: Results of 3 DOF torsion flexible joint stiffness matrixes

\begin{tabular}{lcccc}
\multicolumn{1}{c}{ Axis } & $\mathbf{X}$ & $\mathbf{Y}$ & $\mathbf{Z}$ \\
\hline $\begin{array}{l}\text { Experimental twist } \\
\text { angle (Degree) }\end{array}$ & 0.133 & 0.090 & 0.139 \\
\hline $\begin{array}{l}\text { FE. Twist angle (De- } \\
\text { gree) }\end{array}$ & 0.109 & 0.060 & 0.055 \\
\hline$\theta_{\mathrm{i}}($ Degree) & 0.024 & 0.030 & 0.084 \\
\hline $\begin{array}{l}\text { Moment, } \mathrm{M}_{\mathrm{i}} \\
\text { (N-mm) }\end{array}$ & 92,086 & 128,167 & 128,167 \\
\hline $\begin{array}{l}\text { Torsion flexible joint } \\
\text { parameter value }\left(\mathrm{M}_{\mathrm{i}} / \theta_{\mathrm{i}}\right) \\
(\mathrm{N}-\mathrm{mm} . / \text { degree) }\end{array}$ & $3,727,007$ & $4,203,535$ & $1,531,948$ \\
\hline
\end{tabular}

Table 8: Results of 3 DOF linear flexible joint stiffness matrixes (23-mm x 48.5-mm x 2-mm)

\begin{tabular}{lcccc}
\hline & X direction & Y direction & $\begin{array}{c}\text { Z direc- } \\
\text { tion }\end{array}$ \\
\hline $\begin{array}{l}\text { Experimental deformation at } \\
\text { joint }(\mathrm{mm})\end{array}$ & 0.850 & 0.344 & 0.220 \\
\hline $\begin{array}{l}\text { FE. deformation at joint } \\
(\mathrm{mm})\end{array}$ & 0.152 & 0.127 & 0.145 \\
\hline $\mathrm{d}_{\mathrm{x}}(\mathrm{mm})$ & 0.698 & 0.217 & 0.075 \\
\hline Load, $\mathrm{F}_{\mathrm{x}}(\mathrm{N})$ & 127.53 & 127.53 & 127.53 \\
\hline $\begin{array}{l}\text { Linear flexible joint Parame- } \\
\text { ter value }\left(\mathrm{F}_{\mathrm{i}} / \mathrm{d}_{\mathrm{i}}\right)(\mathrm{N} / \mathrm{mm} .)\end{array}$ & 182 & 588 & 1,700 \\
\hline
\end{tabular}

Table 9: Results of 3 DOF torsion flexible joint stiffness matrixes

\begin{tabular}{lccc}
\multicolumn{1}{c}{ Axis } & $\mathbf{X}$ & $\mathbf{Y}$ & $\mathbf{Z}$ \\
\hline $\begin{array}{l}\text { Experimental twist } \\
\text { angle (Degree) }\end{array}$ & 0.258 & 0.678 & 0.604 \\
\hline $\begin{array}{l}\text { FE. Twist angle (De- } \\
\text { gree) }\end{array}$ & 0.178 & 0.588 & 0.523 \\
\hline$\theta_{\mathrm{i}}($ Degree) & 0.080 & 0.090 & 0.081 \\
\hline $\begin{array}{l}\text { Moment, } \mathrm{M}_{\mathrm{i}} \\
(\mathrm{N}-\mathrm{mm})\end{array}$ & 13,901 & 122,046 & 122,046 \\
\hline $\begin{array}{l}\text { Torsion flexible joint } \\
\text { parameter value }\left(\mathrm{M}_{\mathrm{i}} / \theta_{\mathrm{i}}\right)\end{array}$ & 174,810 & $1,353,521$ & $1,497,636$ \\
$(\mathrm{~N}-\mathrm{mm} . /$ degree $)$ & & & \\
\hline
\end{tabular}

Table 10: Results of 3 DOF linear flexible joint stiffness matrixes

\begin{tabular}{l|c|c|c}
\hline \multicolumn{4}{c}{$(25.6-\mathrm{mm} \times 25.6-\mathrm{mm} \times 2-\mathrm{mm})$} \\
\hline $\begin{array}{l}\text { Experimental defor- } \\
\text { mation at joint }(\mathrm{mm})\end{array}$ & X direction & Y direction & $\begin{array}{c}\text { Z direc- } \\
\text { tion }\end{array}$ \\
\hline $\begin{array}{l}\text { FE. deformation at joint } \\
(\mathrm{mm})\end{array}$ & 0.1332 & 0.398 & 0.136 \\
\hline $\mathrm{d}_{\mathrm{x}}(\mathrm{mm})$ & 0.202 & 0.257 & 0.121 \\
\hline Load, $\mathrm{F}_{\mathrm{x}}(\mathrm{N})$ & 83.385 & 0.141 & 0.015 \\
\hline $\begin{array}{l}\text { Linear flexible joint } \\
\text { Parameter value }\left(\mathrm{F}_{\mathrm{i}} / \mathrm{d}_{\mathrm{i}}\right)\end{array}$ & 413 & 593 & 83.385 \\
\hline \begin{tabular}{l}
$\mathrm{N} / \mathrm{mm})$. \\
\hline
\end{tabular} & & & 5,559 \\
\hline
\end{tabular}

Table 11: Results of 3 DOF torsion flexible joint stiffness matrixes

\begin{tabular}{c|c|c|c}
\multicolumn{4}{c}{$(25.6-\mathrm{mm} \times 25.6-\mathrm{mm} \times 2-\mathrm{mm})$} \\
\hline \multicolumn{1}{c}{ Axis } & $\mathbf{X}$ & $\mathbf{Y}$ & $\mathbf{Z}$ \\
\hline $\begin{array}{l}\text { Experimental twist } \\
\text { angle (Degree) }\end{array}$ & 0.552 & 0.533 & 0.967 \\
\hline
\end{tabular}




\begin{tabular}{l|c|c|c}
\hline $\begin{array}{l}\text { FE. Twist angle }(\mathrm{De}- \\
\text { gree })\end{array}$ & 0.378 & 0.503 & 0.910 \\
\hline$\theta_{\mathrm{i}}(\mathrm{Degree})$ & 0.174 & 0.030 & 0.057 \\
\hline $\begin{array}{l}\text { Moment, } \mathrm{M}_{\mathrm{i}} \\
(\mathrm{N}-\mathrm{mm})\end{array}$ & 14,359 & 79,582 & 79,582 \\
\hline $\begin{array}{l}\text { Torsion flexible joint } \\
\text { parameter value }\left(\mathrm{M}_{\mathrm{i}} / \theta_{\mathrm{i}}\right) \\
(\mathrm{N}-\mathrm{mm} . / \text { degree })\end{array}$ & 82,650 & $2,694,863$ & $1,400,193$ \\
\hline
\end{tabular}

\subsection{Strength Analysis of a Bus Superstructure}

\subsubsection{Maximum Stress and Maximum Deformation}

For the strength analysis, the maximum stress occurred on the FE beam model of bus superstructure with rigid joint and flexible joint were considered. Comparatively, the results revealed that the magnitude of maximum stress in a case of FE beam model with flexible joint exhibited as $44.57 \mathrm{MPa}$ in the bending load case, which was decreasing of $5.72 \%$ as comprised to the case of rigid joint model. This results due to the effect of beam joint behavior which can be flexible structures. However, the value of maximum stress in a case of FE flexible joint was higher than the case of rigid joint model following as $81.94 \mathrm{MPa}, 28.22 \mathrm{MPa}$, and 34.06 $\mathrm{MPa}$ (with increasing of $11.53 \%, 14.11 \%$, and $18.45 \%$ ) in the torsion, longitudinal, and lateral load case, respectively. However, it was not over the yield strength of material following as 235 $\mathrm{MPa}$ and $370 \mathrm{MPa}$ for chassis frame, and body structure, respectively.

Figure 8 displayed the maximum stress distribution occurred on the bus superstructure in a case of torsion load, which was the critical condition. The critical stress of $81.94 \mathrm{MPa}$ occurred on the cross beam member of body structure which was adjacent to rear wheel hub. According to the failure, the safety factor of body structural disclosed the value of 2.87 in a case of twist behavior. Generally, the safety factor recommended from previous research should be more than 2.5 [5]. However, different vehicle will experience different torsion loads, for a given bump height, depending on their mechanical and geometry characteristic [3].

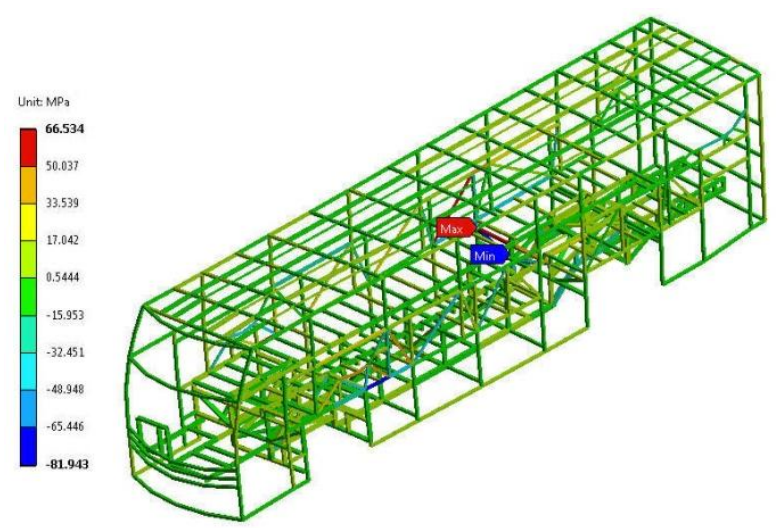

Fig. 8: Maximum stress distribution occurred on the body structure in a case of torsion load.

In order to compare maximum deformation, there was no threshold values for the deformation of bus superstructure but it was importance value for calculate the stiffness of superstructure, the results exhibited that the FE beam model with rigid joint model displayed the highest deformation in a bending load case. In the other hand, the FE beam model with flexible joint model showed the highest deformation in a case of lateral load. For the magnitude of maximum deformation, the FE model with flexible joint simulation showed following as $10.17 \mathrm{~mm}, 6.07 \mathrm{~mm}$, and 22.12 $\mathrm{mm}$ in a case of bending, longitudinal, and lateral displayed, respectively.

\subsubsection{Bus superstructure stiffness}

The construction stiffness of a vehicle structure has important influences on its handling and vibration behavior, including the benchmark of vehicle structure performance [3]. Different load cases require different stiffness definition; however, the two most commonly used included the bending stiffness and torsion stiffness.

According to the bending stiffness, it was found that the bus superstructure with FE beam with flexible joint showed the bending stiffness of $5,959 \mathrm{~N} / \mathrm{mm}$ which was lower than rigid joint simulation $44.85 \%$. For the torsion stiffness, the FE result revealed that the FE beam model with flexible joint simulation displayed as $19,303 \mathrm{~N}$-m/degree which was the lower value than the FE rigid joint model of $10.68 \%$. Again, this result was due to the effect of beam joint modelling. Regarding the vehicle structure stiffness, there was no previous report about the proper value. However, the bending stiffness was recommended with the range of 5,000 $\mathrm{N} / \mathrm{mm}-15,000 \mathrm{~N} / \mathrm{mm}$ for the common vehicle structure. while, the torsion stiffness for bus structure was suggested as 18,000 $40,000 \mathrm{~N}-\mathrm{m} /$ degree. [10-13]

\section{Conclusion}

This study focused on analyzing a bus superstructure in term of strength analysis including the structural stiffness. One model of the intercity bus made from Cherdchai Industrial Factory Co.,Ltd. was employed in the study. The FE beam model was proposed for the accuracy improvement of T-junction of joint stiffness. Using the equivalent flexible joint stiffness, FE beam model of bus superstructure was carried out based on the vehicle global load cases (e.g., bending, torsion, longitudinal and lateral conditions). According to the results, the flexible joint stiffness consideration has been obtained, in which the behavioral error was reduced to less than $6 \%$. For the strength analysis, the magnitude of maximum stress in the improved beam joint model displayed increasing of $11.53 \%, 14.11 \%$, and $18.45 \%$ in torsion, longitudinal and lateral load cases, respectively. However, it did not exceed the yield stress. The bending and torsion stiffness of bus superstructure displayed as 5,959 N/mm and 19,303 N-m/degree which was lower than the FE beam model with rigid joint analysis. By this way, the accuracy improvement of FE beam joint modelling will be beneficial for the passenger and the bus structure design and development procedure.

\section{Acknowledgement}

The authors would like to acknowledge the Center of Scientific and Technological Equipment, Suranaree University of Technology, and the Faculty of Engineering, Chaiyaphum Rajabhat University. The authors also would like to thank Cherdchai Industrial Factory Co.,Ltd. for the sincere support among the research activities of this article.

\section{References}

[1] DLT. 2012. Transport Statistic Report of Thailand. Department of Land Transport. Thailand, available online: http://apps.dlt.go.th/statistics_web.html, last visit: 13.04. 2014

[2] Adams, V., and Askenazi, A., Building Better Products with Finite Element Analysis. OnWord Press Santa Fe. (1998)

[3] Jason, C. B., A. John, R. and Stan, T. S., Motor vehicle structuresconcepts and fundamentals. Oxford: Butterworth-Heinemann. (2002)

[4] Julian, H. S., An introduction to modern vehicle design. Oxford: Butterworth-Heinemann. (2002)

[5] Gauchia, A., Diaz, V., Boada, L. and Boada, B. (2010), Torsional stiffness and weight optimization of a real bus structure. International Journal of Automotive Technology. 11(1): 41-47. 
[6] Lan, F., Chen, J. and Lin, J. (2004), Comparative analysis for bus side structures and lightweight optimization. Proceedings of the Institution of Mechanical Engineers, Part D: Journal of Automobile Engineering. 218(10): 1067-1075.

[7] Balázs, G. (2005), Dynamic analysis of a bus body frame: Determination of the loads and stresses. Vehicle System Dynamics. 43(11): 807-822.

[8] Milojevic, S. and Pesic R. (2012), Theoretical and experimental analysis of a CNG cylinder rack connection to a bus roof. International Journal of Automotive Technology. 13(3): 497-503.

[9] Alcala', E., Badea , F., Martin Á. and Aparicio F. (2013), Methodology for the accuracy improvement of FEM beam type T-junctions of buses and coaches structures. International Journal of Automotive Technology. 14(5): 817-827.

[10] Bosch GmbH, R., Automotive Handbook. 7th edn. Massachusetts: Bentley Publishers. (2007)

[11] Croccolo, D., Agostinis , M.D. and Vincenzi , N. (2011), Structural Analysis of an Articulated Urban Bus Chassis via FEM: a Methodology Applied to a case study. Journal of Mechanical Engineering. 57(11): 799-809.

[12] Helsen J., Cremers, L., Mas P., and Sas P. (2010), Global static and dynamic car body stiffness based on a single experimental modal analysis test. Proceedings of the International Conference on Noise and Vibration Engineering, Leuven, Belgium. 20-22 September 2010. 2505-2521

[13] Jain, R., Tandon, P. and Vasantha Kumar, M. 2014. Optimization methodology for beam gauges of the bus body for weight reduction. Applied and Computational Mechanics. 8(2014): 47-62. 